\title{
The control of nucleolus volume in wheat, a genetic study at three developmental stages
}

\author{
Guido Martini* and Richard Flavell
}

Plant Breeding Institute, Trumpington, Cambridge CB2 2LQ

\begin{abstract}
The major nucleoli in the wheat variety Chinese Spring are formed at the nucleolus organisers (NORs) on chromosomes 1B and 6B. Minor nucleoli are formed from the NORs on chromosomes 5D and 1A. Nucleolar volume is poorly correlated with the number of ribosomal RNA genes in the NOR region. The nucleolus on chromosome 1B is twice the volume of that on chromosome $6 \mathrm{~B}$ even though only half as many ribosomal RNA genes reside at the $1 \mathrm{~B}$ locus compared with the number at the $6 \mathrm{~B}$ locus. Nucleolus size is correlated with the size of the NOR constriction seen in metaphase chromosomes. When major NORs are deleted, the volumes of the remaining nucleoli increase to compensate for the deletions. Varying the dosage of many of the chromosomes in the total complement influences the volume of the minor nucleoli. Chromosomes $1 \mathrm{D}$ and $6 \mathrm{~B}$ have been shown to carry genes regulating total nucleolar volume. Although total nucleolar volume differs between cells at different stages of development, the genetic variation influencing volume appears to have similar effects in root tip, premeiotic and young pollen cells.
\end{abstract}

\section{INTRODUCTION}

Nucleoli are the sites of synthesis of ribosome precursor particles (Birnstiel et al., 1971). They form at the chromosomal sites (nucleolus organiser, NOR) of the $18 S, 5 \cdot 8 S$ and $25 \mathrm{~S}$ ribosomal RNA genes. The rRNA gene transcripts are synthesised, methylated and processed in the nucleolus and presumably associate with the ribosomal proteins and 5S RNA (Maden et al., 1982). $5 S$ RNA is not essential for nucleolus formation, however (Weber 1978). The nucleolus contains the tandemly repeating ribosomal DNA units in regions known as fibrillar centres. Around the centres are regions (fibrillar components) where transcription occurs. Other portions of nucleoli are more granular and probably contain mature ribonucleoprotein particles. Intermeshed between these components is a skeletal structure (see articles in Jordan and Cullis 1982).

Since most of the mass and volume of the nucleolus is made up of rDNA chromatin, structures connected with its transcription and processing, and assembled ribonucleoprotein particles, the

* On leave from: Istituto di Mutagenesis e Differenziamento del C.N.R., Via Svesia, 10, 56100 Pisa, Italy. volume of a nucleolus appears to be a useful guide to the activity of ribosome precursor particle synthesis occurring around a particular NOR. The precise relationship between nucleolar volume and transcription and how it varies in different developmental states is not known. However, in some organisms at particular developmental stages, evidence for a close correlation between nucleolus volume and rRNA synthesis has been reported (Miller and Knowland 1970; Shermoen and Kiefer, 1975).

In a previous paper (Flavell and O'Dell, 1979) we showed that the volume of a nucleolus in root tip cells

(1) is not invariably related to the number of rRNA genes at the NOR

(2) varies with the number of other NORs in the cell and

(3) is also affected by genes on chromosomes not carrying a NOR.

These conclusions were drawn from counting the number of visible nucleoli per cell in different genotypes. No measurements of nucleolar volume were reported. In this paper we report such measurements in root tip cells, in pachytene cells and in developing microspores of genotypes 
possessing known numbers of rRNA genes at defined NORs. The results have enabled the genetic control of nucleolus volume in wheat to be described more quantitatively.

\section{MATERIALS AND METHODS}

\section{Genotypes Studied}

Seeds of the wheat variety Chinese Spring and the aneuploid derivatives were originally obtained from Dr E. R. Sears, University of Missouri (Sears 1954). Genotypes with an additional pair of homologous chromosomes are designated tetrasomic ( $T$ ) for that chromosome. Those carrying a homologous pair of chromosomes with one arm deleted are designated ditelosomic (DT). Compensated nullisomic-tetrasomic lines with a pair of homologous chromosomes deleted and an additional pair of chromosomes homoeologous to those deleted are termed N-T .

The Chinese Spring lines carrying chromosome $1 \mathrm{U}$ from Aegilops umbellulata in place of chromosomes $1 \mathrm{~A}, 1 \mathrm{~B}$ or $1 \mathrm{D}$, or in addition to the Chinese Spring chromosome complement were developed by $\mathrm{Mr}$ V. Chapman of this Department.

\section{Growth of seedlings for root cell assays}

Seeds of each genotype were sterilised by soaking for about 10 mins in 2 per cent sodium hypochlorite and washed several times in sterile water. After imbibition on moist filter paper at $3^{\circ} \mathrm{C}$ for 48 hours, they were incubated at $25^{\circ} \mathrm{C}$ for 2 days. Root tips were fixed in Rattenbury's fixative (ethanol:formaldehyde:glacial acetic acid 13:6:1; Rattenbury, 1952) for 24 hours and stored in 70 per cent ethanol.

\section{Growth of plants for pachytene and microspore analysis}

Seeds were germinated in petri dishes, then transplanted into compost in 5 inch pots and grown in a glasshouse at approximately $20^{\circ} \mathrm{C}$ under continuous artificial light. After approximately four weeks (before meiosis) the plants were transferred to a growth chamber at a temperature of $20^{\circ} \mathrm{C}$ with a photoperiod regime of 18 hours light 6 hours darkness. Three plants of each genotype were arranged randomly in the chamber. Spikes at the appropriate developmental stage were fixed in Rattenbury's fixative (see above) and stored in 70 per cent ethanol.

\section{Staining of nucleoli and measurements of nucleolar volume}

Root tips and anthers were hydrolysed at $60^{\circ} \mathrm{C}$ in $1 \mathrm{~N} \mathrm{HCl}$ for 2 hours and teased apart on a glass slide in a drop of acetocarmine stain. A coverslip was placed on top of the cells without pressure to avoid squashing the nucleoli. The volume $(V)$ of nucleoli was calculated from the formula $V=$ $(4 \pi / 3)(D+d)^{3} / 64$ after two diameters $(D$ and $d)$ had been measured at right angles.

\section{RESULTS}

The NOR on chromosome $1 B$ makes a larger nucleolus than the NOR on chromosome $6 B$

Cells of Chinese Spring wheat have two pairs of major nucleoli specified by the NORs of chromosomes $1 \mathrm{~B}$ and $6 \mathrm{~B}$ and two minor pairs specified by the NORs of chromosomes 5D and IA (Longwell and Svihla 1960). Measurements of the volumes of the major nucleoli in root tip cells which display four major nucleoli (this avoids measuring fused nucleoli, Jordan et al., 1982) shows that they fall into two discrete classes, with the nucleoli in one class being approximately twice as large as those in the other (fig. 1). To determine whether the NORs on chromosomes $1 \mathrm{~B}$ or $6 \mathrm{~B}$ specify the larger nucleoli, root tip and pollen cells from plants with different doses of chromosomes $1 \mathrm{~B}$ and $6 \mathrm{~B}$ were scored for the frequency of large and small nucleoli. In plants with an additional pair of $1 \mathrm{~B}$ chromosomes (tetrasomic 1B) 70 per cent of the root cells displayed an extra pair of the larger nucleoli (see cell in fig. 2B). In the plants with one $1 \mathrm{~B}$ chromosome deleted (monosomic 1B)

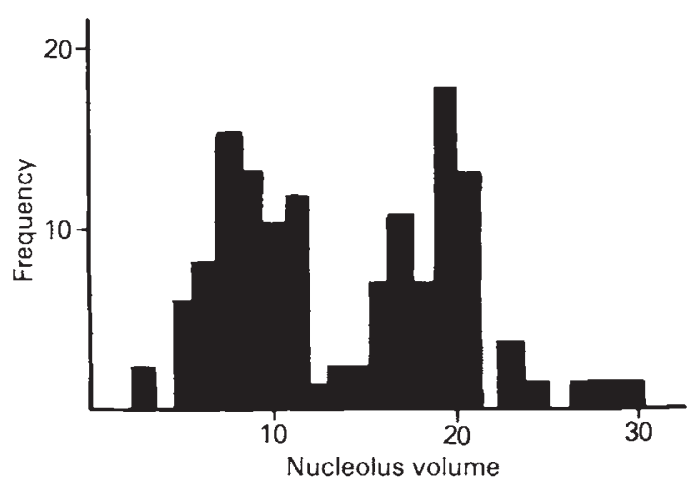

Figure 1 Relative volumes of major nucleoli in Chinese Spring root tip cells. The volumes of nucleoli in root tip cells possessing four major nucleoli were measured as described in Materials and Methods. 


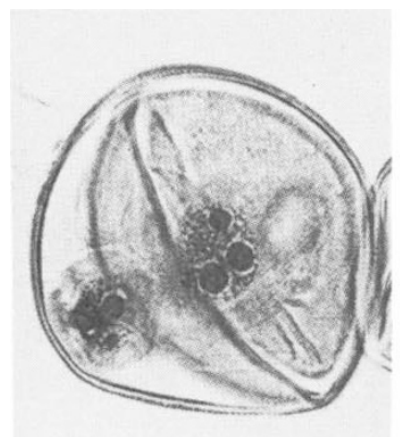

A

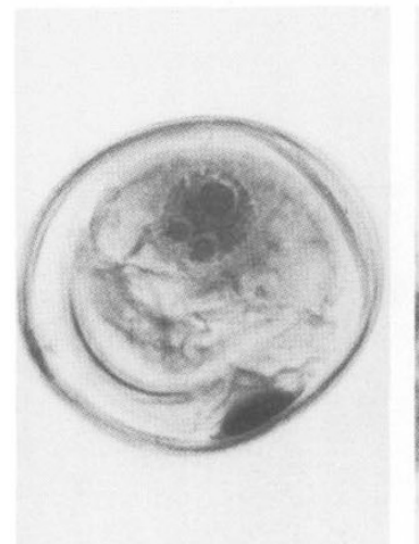

D

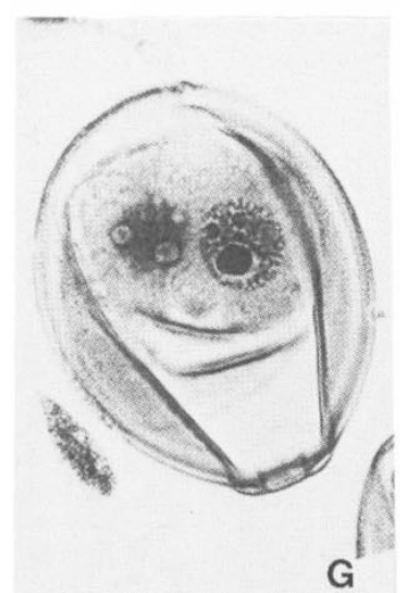

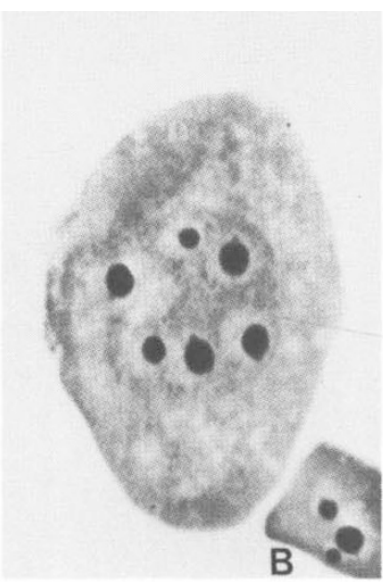
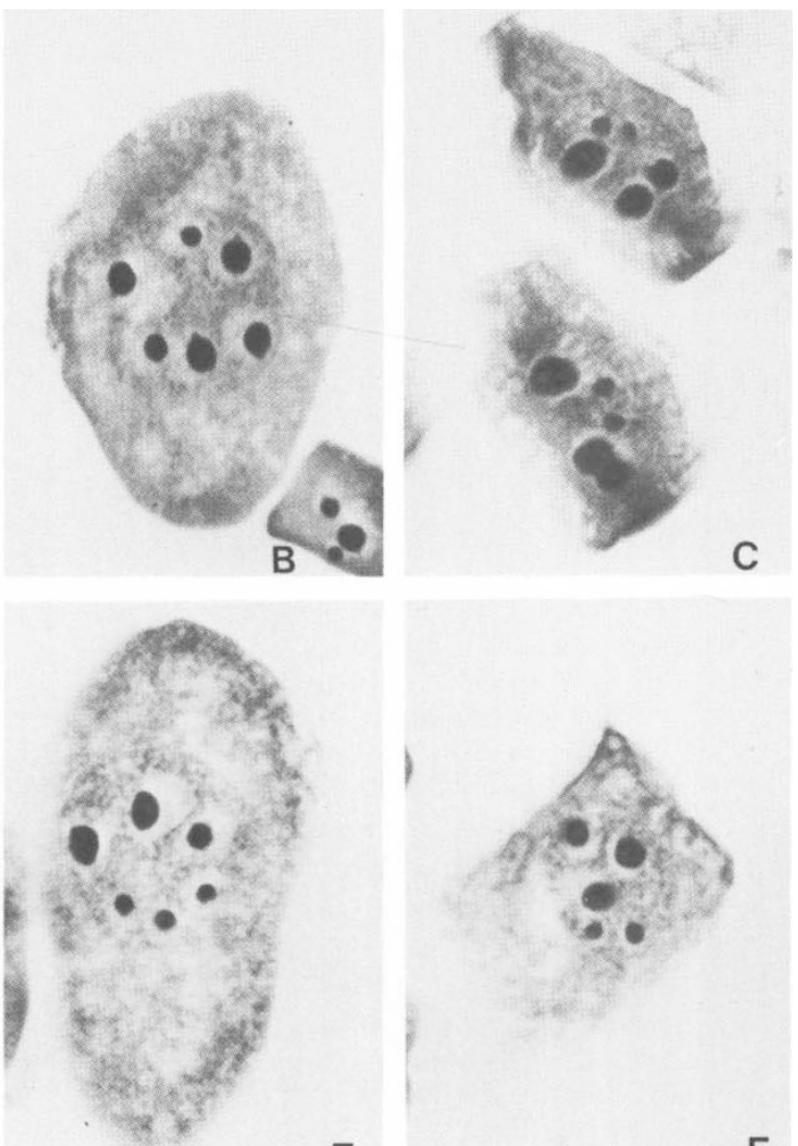

E
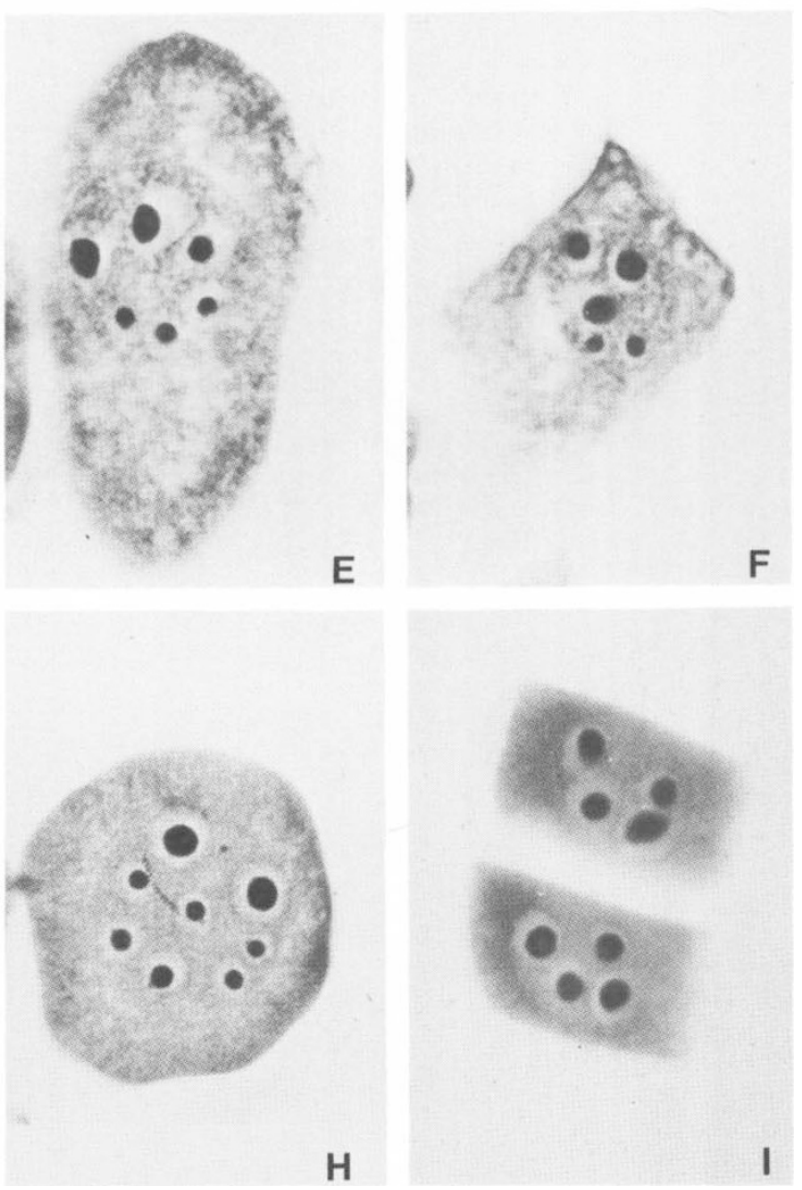

Figure 2 Nucleoli in cells of different genotypes. A. Pollen soon after 1st pollen division in tetrasomic 1 B line, showing two large (1B) and one smaller (6B) nucleolus. B. Root tip cell of tetrasomic 1B showing four large (1B) and two smaller (6B) nucleoli. C. Root tip cells of monosomic 1B showing one large (1B), two smaller (6B) nucleoli and two micronucleoli (5D). D. Pollen soon after Ist pollen division in tetrasomic 6B showing two smaller $(6 \mathrm{~B})$ and one large $(1 \mathrm{~B})$ nucleolus. E. Root tip cell of tetrasomic 6B showing two large (1B) and four smaller (6B) nucleoli. F. Root tip cell of monosomic 6B showing two large (1B), one smaller (6B) nucleoli and two micronucleoli (5D). G. Pollen soon after first division of tetrasomic 5D showing one large (1B), one smaller (6B) nucleolus and two micronucleoli (5D). H. Root tip cell of tetrasomic 5D showing two large (1B) nucleoli, two smaller 6B nucleoli and the four small nucleoli from the 5D chromosomes. I. Root tip cell of Chinese Spring euploid showing two $1 \mathrm{~B}$ and two $6 \mathrm{~B}$ nucleoli. 

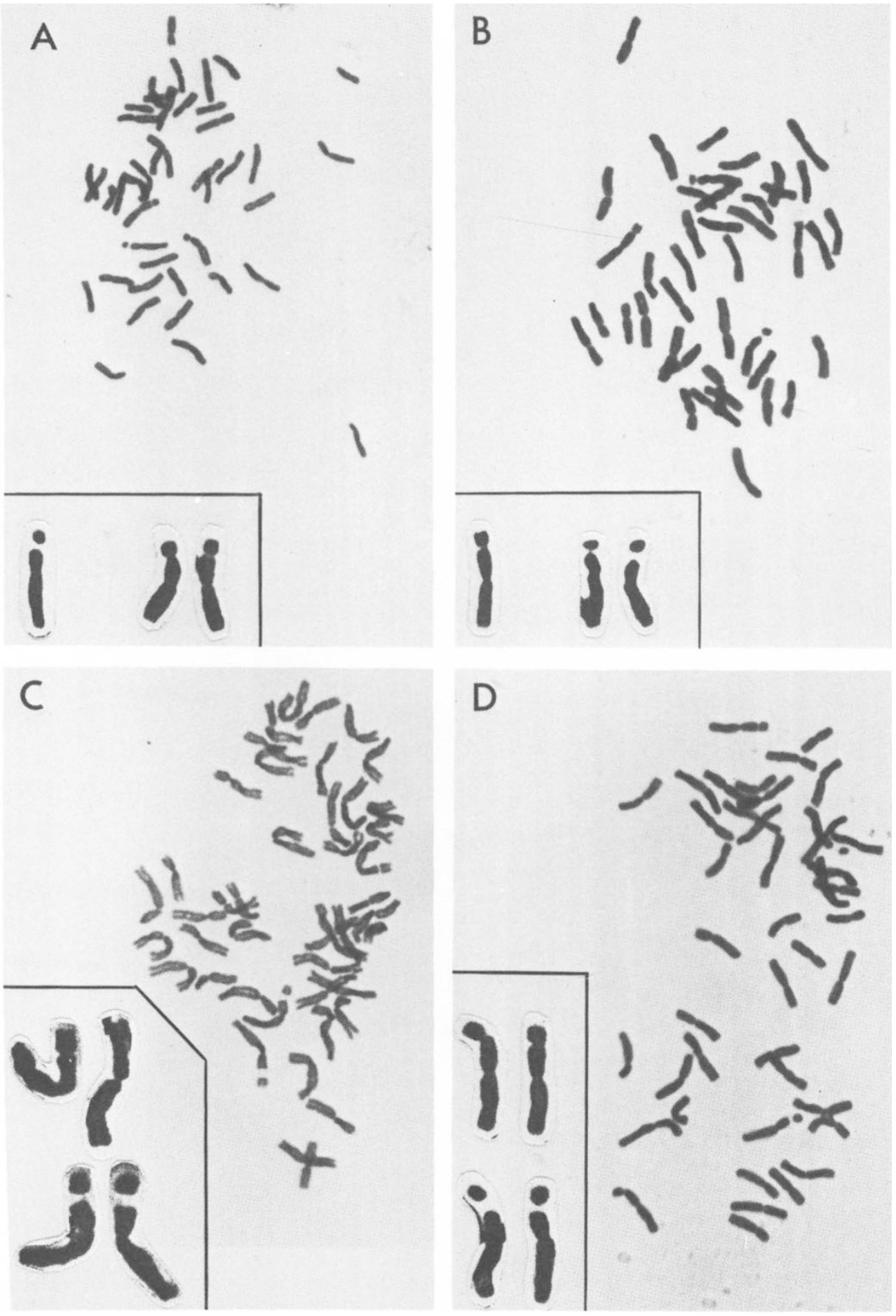

Figure 3 Metaphase chromosomes in root tip cells of different genotypes showing nucleolar constrictions.
A Monosomic 1B
B Monosomic 6B
C Tetrasomic 5D
D Chinese Spring euploid

The chromosomes showing nucleolar constriction (1B and $6 \mathrm{~B}$ ) are also shown magnified to illustrate the relative size of the constrictions. The chromosomes were paired on the basis of size, arm ratios and length of satellite. 
67 per cent of the root tip cells had only one large nucleolus (see cell in fig. $2 \mathrm{C}$ ). In most root cells (76 per cent) of plants with an additional pair of 6B chromosomes (tetrasomic 6B), an additional pair of the smaller nucleoli were found (see cell in fig. 2E) while in 72 per cent of cells with one 6B chromosome deleted, one of the smaller nucleoli was absent (see cell in fig. $2 \mathrm{~F}$ ).

In haploid pollen cells, the presence of an extra 1B chromosome most frequently (in 74 per cent of cells) resulted in an additional large nucleolus (see cell in fig. 2A) while the presence of an extra 6B chromosome resulted in another smaller nucleolus (see cell in fig. 2D).

These results imply that of the four major nucleoli in euploid Chinese Spring the larger pair is usually made on chromosome $1 \mathrm{~B}$ and the smaller pair on chromosome $6 \mathrm{~B}$. This conclusion was also drawn from a study of the length of the NOR constrictions in metaphase chromosomes.

The lengths of the satellite, secondary constriction, short arm and long arms of $1 \mathrm{~B}$ and $6 \mathrm{~B}$ metaphase chromosomes were measured in 34 and 38 photographs respectively of Chinese Spring euploid, monosomic 1B, monosomic $6 \mathrm{~B}$ or tetrasomic 1B genotypes (sample photographs are shown in fig. 3). The $1 \mathrm{~B}$ and $6 \mathrm{~B}$ chromosomes could be distinguished from each other by the length of their short arms (see table 1) and also

Table 1 Lengths of arms and NOR constriction in metaphase $1 \mathrm{~B}$ and $6 \mathrm{~B}$ chromosomes

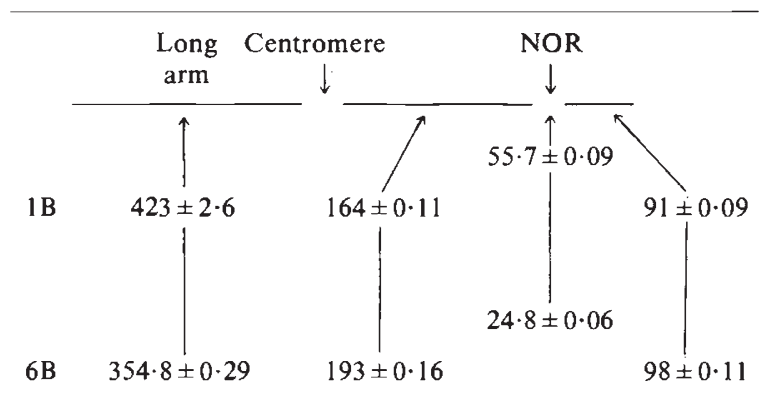

The lengths of the chromosome arms and NOR constrictions (in arbitrary units) were taken from photographs of metaphase chromosomes magnified to the same extent (see fig. 3 and text).

by the number of copies of each chromosome in the aneuploid stocks. The results are expressed in table 1 in arbitrary units. Overall the secondary constriction of chromosome $1 \mathrm{~B}$ was $8 \cdot 2$ per cent of the chromosome length while that of chromosome $6 \mathrm{~B}$ was 3.8 per cent of the chromosome length. Chromosomes $1 \mathrm{~B}$ and $6 \mathrm{~B}$ are very similar in length, which implies that the NOR constriction of chromosome $1 \mathrm{~B}$ is about twice the size of that of chromosome $6 \mathrm{~B}$. The constriction length therefore correlates with the nucleolus volume difference between $1 \mathrm{~B}$ and $6 \mathrm{~B}$ chromosomes. The metaphase constriction is not really a constriction at all. It consists of pale-staining fibrillar material (Goessens and Lepoint, 1974). This fibrillar material may be very similar to that in the fibrillar centre of the interphase nucleolus. The amount of this in the metaphase chromosome (in terms of length of non-stained region i.e., constriction) may therefore be a useful guide to the amount of rDNA chromatin incorporated into a nucleolus in the preceding interphase. If so, we can conclude that twice as much rDNA chromatin from chromosome $1 \mathrm{~B}$ was incorporated into its nucleolus compared with that incorporated from chromosome $6 \mathrm{~B}$. This needs to be examined further by other means. The conclusion that the NOR of chromosome $1 \mathrm{~B}$ makes a larger nucleolus than that of chromosome $6 \mathrm{~B}$ is especially interesting because the $1 \mathrm{~B}$ NOR has half the number of rRNA genes as the 6B NOR (Flavell and O'Dell 1976).

\section{The minor NORs are activated when major NORs are deleted and in certain other aneuploid genotypes}

Previous scores of the total and mean number of nucleoli per cell in root tip cells have shown that when a major NOR is deleted, minor NORs are activated and this activation also occurs in certain aneuploid genotypes in which the number of NORs does not vary (Flavell and O'Dell, 1979).

These results have now been re-examined in more detail by scoring separately the micronucleoli and macronucleoli in root tip cells and by studying root tip cells in Gl early after telophase. Such cells offer the advantage that nucleolus fusion has hardly begun and using them should eliminate the possibility that the variation in mean nucleolus number described previously (Flavell and O'Dell, 1979) was due to variation in the extent of nucleolus fusion. The activation of minor NORs has also been re-examined by measuring nucleolar volumes.

The percentage of root tip cells carrying visible micronucleoli is shown in table 2 for a range of genotypes. In Chinese Spring euploid the value was 22 per cent, with 35 per cent of these cells showing more than two minor nucleoli. Since there is a major reduction in the percentage of cells carrying visible micronucleoli when chromosome $5 \mathrm{D}$ is deleted (as in N5DT5A; table 2) we conclude that the larger, more visible micronucleoli in the 
Table 2 Numbers of NORs and nucleoli in different wheat genotypes

\begin{tabular}{|c|c|c|c|c|c|c|c|c|}
\hline Genotype & $\begin{array}{l}\text { No. of } \\
\text { major } \\
\text { NORs } \\
(1 \mathrm{~B}+6 \mathrm{~B})\end{array}$ & $\begin{array}{l}\text { No. of } \\
\text { minor } \\
\text { NORs } \\
(5 \mathrm{D}+1 \mathrm{~A})\end{array}$ & $\begin{array}{l}\text { Total } \\
\text { cells } \\
\text { scored }\end{array}$ & $\begin{array}{l}\% \text { of cel } \\
\text { Macro- } \\
\text { nucleoli } \\
\text { only }\end{array}$ & $\begin{array}{l}\text { ith: } \\
\text { Macro- } \\
\text { nucleoli } \\
\text { + micro } \\
\text { nucleoli }\end{array}$ & $\begin{array}{l}\% \text { of cel } \\
2 \\
\text { micro- } \\
\text { nucleoli } \\
\text { (5D) }\end{array}$ & $\begin{array}{l}\text { ith: } \\
4 \\
\text { micro- } \\
\text { nucleoli } \\
(5 \mathrm{D}+1 \mathrm{~A})\end{array}$ & $\begin{array}{l}\text { Mean } \\
\text { no. } \\
\text { nucleoli/ } \\
\text { cell }\end{array}$ \\
\hline Chinese Spring & 4 & 4 & 887 & 78 & 22 & 65 & 35 & $2 \cdot 72$ \\
\hline NIBTIA & 2 & 6 & 210 & 23 & 77 & 59 & 41 & $2 \cdot 64$ \\
\hline N6BT6A & 2 & 4 & 241 & 38 & 62 & 95 & 5 & $2 \cdot 30$ \\
\hline $\mathrm{T} 1 \mathrm{~B}$ & 6 & 4 & 351 & 86 & 14 & 68 & 32 & $3 \cdot 31$ \\
\hline T6B & 6 & 4 & 300 & 86 & 14 & 64 & 36 & $3 \cdot 33$ \\
\hline $\mathrm{T} 1 \mathrm{~A}$ & 4 & 6 & 372 & 74 & 26 & 42 & 58 & $2 \cdot 76$ \\
\hline $\mathrm{DT}_{1 \mathrm{~A}^{1}}$ & 4 & 2 & 301 & 42 & 58 & 100 & - & 3.03 \\
\hline DT $1 A^{s}$ & 4 & 4 & 239 & 82 & 18 & 67 & 33 & $2 \cdot 41$ \\
\hline NIDTIA & 4 & 6 & 341 & 68 & 32 & 47 & 53 & $2 \cdot 79$ \\
\hline DT1D & 4 & 4 & 250 & 55 & 45 & 67 & 33 & $3 \cdot 14$ \\
\hline T5D & 4 & 6 & 306 & 9 & 91 & 95 & 5 & $4 \cdot 50$ \\
\hline N5DT5A & 4 & 2 & 380 & 89 & 11 & 0 & 100 & $2 \cdot 41$ \\
\hline $\mathrm{DT}^{\mathrm{B}} \mathrm{B}^{\mathrm{s}}$ & 4 & 4 & 220 & 29 & 71 & 50 & 50 & 2.95 \\
\hline
\end{tabular}

euploid belong to chromosome 5D. It then follows that the smaller micronucleoli are associated with chromosome $1 \mathrm{~A}$. When a major NOR is deleted (e.g., in NIBTIA or N6BT6A) the percentage of cells carrying micronucleoli increases considerably (table 2), which is due to the micronucleoli being much larger (see below) and therefore more easily visible.
In the root tips of euploid plants no young Gl cells (table 3) were found with fewer than 3 macronucleoli, indicating that both the $1 \mathrm{~B}$ and $6 \mathrm{~B}$ NORs are probably active in every cell. In NIBTIA, NIBTID and N6BT6A, very few of the cells possessed only two or fewer nucleoli, indicating that the 5D NORs are active in almost every cell. In genotypes in which major NORs are duplicated,

Table $3 \%$ of young Gl cells with different numbers of nucleoli in various wheat genotypes

\begin{tabular}{|c|c|c|c|c|c|c|c|c|c|c|c|c|c|c|c|c|}
\hline \multirow[b]{3}{*}{ Genotype } & \multirow{3}{*}{$\begin{array}{l}\text { No } \\
\text { major } \\
\text { NORs }\end{array}$} & \multicolumn{14}{|c|}{ Frequency (in \%) of Nucleoli observed } & \multirow{3}{*}{$\begin{array}{l}\text {-cells } \\
\text { scored }\end{array}$} \\
\hline & & 2 & 2 & 3 & 3 & 4 & 4 & 5 & 5 & 6 & 6 & 7 & 7 & 8 & 8 & \\
\hline & & 1 & 2 & 2 & 3 & 3 & 4 & 4 & 5 & 5 & 6 & 6 & 7 & 7 & 8 & \\
\hline $\mathrm{CS}$ & 4 & & & & & 12 & 76 & 7 & 4 & 1 & & & & & & 116 \\
\hline T1A & 4 & & & & & 6 & 72 & 11 & 9 & 1 & & & & & & 114 \\
\hline TID & 4 & & & & & 5 & 65 & $16 \cdot 5$ & 11 & 2 & & & & & & 101 \\
\hline NIATID & 4 & & & & & 3 & 64 & 17 & 16 & - & & & & & & 118 \\
\hline N1DTIA & 4 & & & & & 2 & 56 & 5 & 27 & 2 & 8 & & & & & 182 \\
\hline $\mathrm{T} 3 \mathrm{~A}$ & 4 & & & & & & & & & 22 & 76 & 2 & & & & 111 \\
\hline T3B & 4 & & & & & & & & & 15 & 83 & 2 & & & & 108 \\
\hline $\mathrm{T} 4 \mathrm{~A}$ & 4 & & & & & & & & & 13 & 84 & 3 & & & & 99 \\
\hline DT $1 \mathrm{~A}$ & 4 & & & & & & & & & 15 & 85 & - & & & & 106 \\
\hline T6B & 6 & & & & & & & & & 16 & 73 & 5 & 5 & 1 & & 126 \\
\hline T1B & 6 & & & & & & & & & 9 & 65 & 15 & 9 & 2 & & 101 \\
\hline N1A TIB & 6 & & & & & & & & & 8 & 56 & 9 & 25 & 2 & & 127 \\
\hline NID TIB & 6 & & & & & & & & & 10 & 79 & 5 & 5 & 1 & & 106 \\
\hline N3A T3B & 4 & & & & & & & & & 8 & 89 & 1 & 2 & - & & 100 \\
\hline T5D & & & & & & & & & & & & & & 44 & 56 & 101 \\
\hline NIB T1A & 2 & & 6 & 8 & 30 & 43 & 13 & & & & & & & & & 156 \\
\hline N1B T1D & 2 & & 4 & 6 & 28 & 50 & 12 & & & & & & & & & 128 \\
\hline N6B T6A & 2 & & 2 & 4 & 25 & 61 & 8 & & & & & & & & & 124 \\
\hline (1B) $1 \mathrm{U}$ & & 5 & 38 & 29 & 21 & 3 & 4 & & & & & & & & & 130 \\
\hline $1 \cup$ Add. & & & 5 & 5 & 3 & 14 & 18 & 4 & 20 & 11 & 10 & & & & & 151 \\
\hline (1D) $1 U$ & & & 1 & 2 & 2 & 15 & 15 & 13 & 25 & 10 & 14 & 1 & 2 & & & 173 \\
\hline (1A)IU & & & & & 6 & 6 & 30 & 16 & 12 & 14 & 6 & 2 & 2 & & & \\
\hline
\end{tabular}

The paired numbers at the top of each column represent the number of nucleoli in paired daughter cells originating in the same cell division 
as in T6B, and TIB, all Gl cells possessed at least five nucleoli indicating the extra NORs are active in every cell (table 3 ). The proportion of cells possessing visible $5 \mathrm{D}$ and $1 \mathrm{~A}$ micronucleoli decreased however, (table 2) which suggests that the activities of the NORs on 5D and 1A are repressed in the presence of more major NORs.

In the earlier study (Flavell and O'Dell, 1979) certain genotypes were found to have higher mean numbers of nucleoli, even though the number of major NORs was not altered from euploid. Some of these genotypes e.g., DTIA ${ }^{\mathrm{L}}, \mathrm{T} 3 \mathrm{~A}, \mathrm{~T} 3 \mathrm{~B}, \mathrm{~T} 4 \mathrm{~A}$ were rescored in this study.

In the young Gl cells of T3A, T3B, T4A no cells were scored with fewer than five nucleoli. Because there is little or no nucleolar fusion in these cells the increase in the mean number of nucleoli is not due to a reduced level of nucleolar fusion compared with in euploid cells (table 3 ). The increased average number is due to a much higher proportion of cells with visible micronucleoli.

Nucleolus volumes were measured in root tip cells displaying the appropriate number of nucleoli i.e., cells in which fusion of the major nucleoli had not occurred. The results are shown in table 4 . In the small proportion of euploid cells in which the $5 \mathrm{D}$ minor nucleoli were visible, they accounted for only about 5 per cent of the total nucleolar volume. In plants with the 6B NORs deleted (N6BT6A) the increase in volume of the minor nucleoli was 3 to 4 fold and it was 2 to 4 fold when chromosomes 1B NORs were deleted (NIBTID, NIBTIA). These increases are responsible for the small NORs on $5 \mathrm{D}$ and $1 \mathrm{~A}$ becoming visible in many more of the cells carrying major NOR deletions (table 1; Flavell and O'Dell 1979). They are underestimates of the real increases in volume because in most cells of the euploid, the minor nucleoli were too small to be measured (table 2).

In the stock with four 5D NORs (T5D), four 5D nucleoli occupied 23 per cent of the total nucleolar volume compared with the 5 per cent occupied by two 5D nucleoli in the uploid. This high value is probably because our tetrasomic $5 \mathrm{D}$ stock carries a deletion of rRNA genes (Flavell and O'Dell 1979). We believe deletions occurred in both $1 \mathrm{~B}$ and $6 \mathrm{~B}$ NORs because the ratio of hybridisation of purified rDNA to the two sites on metaphase chromosomes is not markedly changed from that in euploid cells (unpublished results). Thus the T5D stock also illustrates how the volume of the 5D nucleoli increases following substantial rRNA gene deletion elsewhere in the genome (Flavell and O'Dell 1979). The activation explains why all T5D cells scored early in G1, before fusion, possessed 7 or 8 visible nucleoli (table 3 ). An approximate two fold increase in the percentage volume of the minor nucleoli was measured in the T3B stock, in agreement with a higher number of nucleoli being visible in this genotype (table 3 ).

The increase in the volume of minor nucleoli following deletion of a major NOR, inferred from the increase in the number of visible nucleoli (table 2 ) as well as by direct measurement (table 4), also occurs for the nucleoli of the major $6 \mathrm{~B}$ and $\mathrm{lB}$ NORs. This was inferred from the nucleolar volume measurements shown in table 4 . When the $1 \mathrm{~B}$ NOR was deleted the mean volume of the $6 \mathrm{~B}$ nucleoli increased from about $27 \mu \mathrm{m}^{3}$ to approximately $68 \mu \mathrm{m}^{3}$. When the $6 \mathrm{~B}$ NOR was deleted, the $1 \mathrm{~B}$ nucleolus volume increased from about $53 \mu \mathrm{m}^{3}$ to $107 \mu \mathrm{m}^{3}$. In stocks lacking chromosome $6 \mathrm{~B}$ the increases in volume of the $1 \mathrm{~B}$ and $5 \mathrm{D}$

Table 4 Nucleolar volumes in root tip cells of various genotypes

\begin{tabular}{|c|c|c|c|c|}
\hline \multirow[b]{2}{*}{ Genotype } & \multicolumn{4}{|c|}{ Nucleolar volume in roots $\left(\mu \mathrm{m}^{3}\right)$} \\
\hline & $1 \mathrm{~B}$ & $6 \mathrm{~B}$ & $5 D^{*}$ & Total \\
\hline N6B T6A & $107 \pm 2 \cdot 38(80 \cdot 7 \%)$ & - & $25 \cdot 5 \pm 0.53(19.3 \%)$ & $132 \cdot 5$ \\
\hline N1B TID & & $70 \cdot 5 \pm 2 \cdot 19(88 \cdot 0 \%)$ & $9 \cdot 5 \pm 0 \cdot 34(12 \cdot 0 \%)$ & 80 \\
\hline NIB T1A & & $68 \pm 1 \cdot 88(79 \cdot 5 \%)$ & $16 \cdot 5 \pm 0 \cdot 66(20 \cdot 5)$ & $84 \cdot 5$ \\
\hline N1D T1A & $69 \cdot 8 \% \pm 1 \cdot 18$ & $30 \cdot 2 \% \pm 1 \cdot 18$ & & \\
\hline NIA TID & $61.7 \% \pm 0.93$ & $38 \cdot 3 \% \pm 0 \cdot 93$ & & \\
\hline T1A & $66 \cdot 8 \% \pm 0 \cdot 88$ & $33 \cdot 2 \% \pm 0 \cdot 88$ & & \\
\hline T1D & $66.3 \% \pm 0.95$ & $33.7 \% \pm 0.95$ & & \\
\hline
\end{tabular}

The nucleolar volumes were determined as described in Materials and Methods.

* The micronucleoli were assumed to originate from chromosome 5D. 1 A nucleoli were too small to contribute significantly to total nucleolar volume. 
nucleoli resulted in a considerable increase in total nucleolar volume compared with the euploid values. This effect is probably due to the simultaneous deletion of a gene on the short arm of chromosome 6B which exerts a suppressing effect on nucleolar volume (see later). In plants lacking $1 \mathrm{~B}$ NORs increases in the volume of $6 \mathrm{~B}$ and $5 \mathrm{D}$ nucleoli restored total nucleolar volume to the euploid value (table 4).

\section{Genetic variation affecting total nucleolar volume acts similarly in root tips, premeiotic cells and in pollen microspores}

The total nucleolar volume per cell was measured in root tip cells possessing one nucleolus due to nucleolar fusion and in meiotic cells at pachytene. Approximately 150 cells were measured in several root tips and approximately 450 pachytene cells from several plants of each genotype grown at $20^{\circ} \mathrm{C}$ in continuous light in a growth chamber. The mean nucleolar volumes for each genotype are plotted against one another in fig. 4. There is significant variation between the genotypes but the values for each genotype at the two developmental stages are highly correlated.

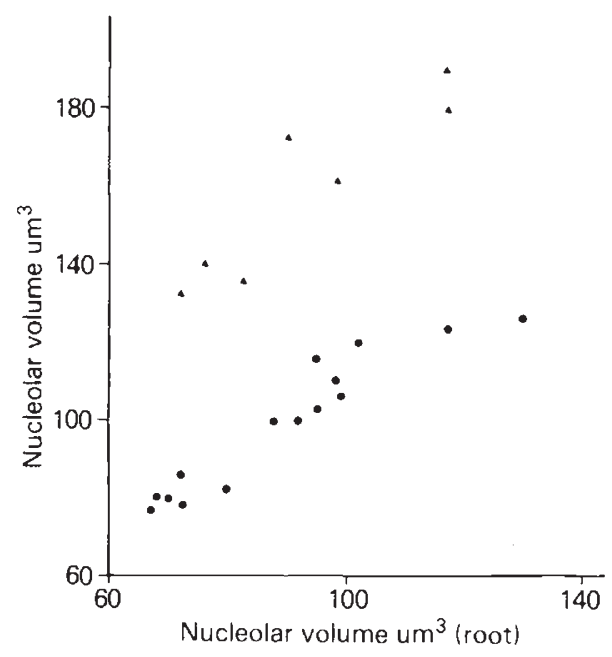

Figure 4 Relationship between total nucleolar volume in root tip, pachytene and young pollen cells in different genotypes. Nucleolar volumes were measured in the appropriate cell types of a range of wheat genotypes (aneuploid varieties and substitution lines) grown as described in Materials and Methods. The results are means of at least 150 cells per plant replicate.

- root vs. pachytene

$\Delta$ root vs. young pollen cell, at 2 nd pollen nuclear division.
During pollen formation from the haploid tetrad cell the nucleolus of the vegetative pollen cell increases in volume very considerably until the second mitotic division, after which it declines to a low level in mature pollen (unpublished results). Because the large volume is formed in a haploid nucleus, it was considered that this might be the developmental stage at which major deletions of rRNA genes might limit nucleolus volume. Total nucleolus volume was therefore measured in cells at or very close to second mitotic division, this nuclear division being used as a developmental marker. The volumes are plotted against those obtained for root tip cells of the same genotypes in fig. 4. The plotted points give a reasonable fit to a straight line passing through the origin. Thus the nucleolus volumes in these genotypes are correlated at the three developmental stages, the largest nucleoli being formed in the haploid microspore around pollen mitosis II.

\section{Nucleolar volume is not correlated with rRNA gene number}

What is the cause of the variation in nucleolus size between genotypes described above? Two possibilities are (1) that the observed variation could reflect a similar variation for the total number of rRNA genes in the genotype, or (2) that other genes regulate nucleolus volume in some other way(s). To test the first possibility, the nucleolar volumes were measured in a range of genotypes in root tip cells and in microspores of genotypes previously determined to differ in the number of rRNA genes. The results are plotted in fig. 5 . There is clearly no strong correlation between

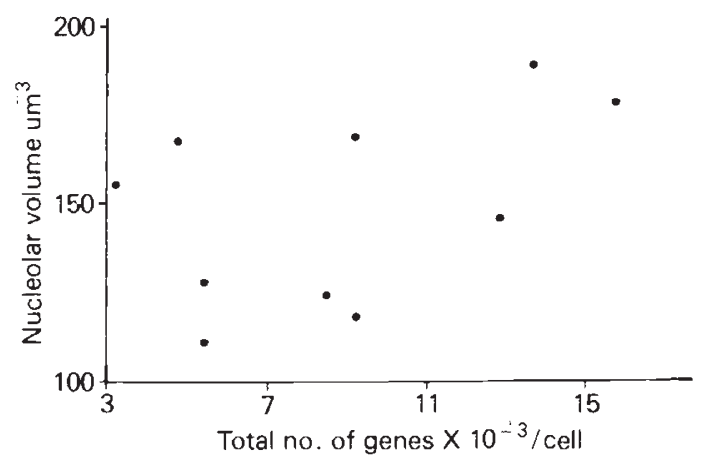

Figure 5 Relationship between nucleolar volume in root tip cells and total number of rRNA genes. The genotypes used have been described previously (Flavell \& O'Dell 1979). Nucleolar volume was measured as described in Methods and Materials. 
mean total nucleolar volume and rRNA gene number-over a range of 3000 to 15,000 rRNA genes per cell. The genotypes with additional major nucleolar organisers (e.g., Tet 1B, 12,800 rRNA genes; Tet 6B 15,700 rRNA genes) all have larger nucleoli than the control genotype (Chinese Spring (9150 rR NA genes)) (see also Longwell and Svihla, 1960) but genotypes with fewer rRNA genes than Chinese Spring frequently display compensation to maintain the nucleolar volumes as large or larger than that of Chinese Spring. Thus even in pollen cells which make an exceptionally large nucleolus with only a haploid complement of genes, major deletions of rRNA genes do not reduce nucleolus volume. It can be seen in figs. 1 and 2 that the NOR chromosome $6 \mathrm{~B}$ makes a smaller nucleolus than that of chromosome $1 \mathrm{~B}$, although it has twice as many rRNA genes. It is therefore likely that other genes are involved in determining nucleolar volume.

\section{Chromosomes $1 D$ and $6 B$ of wheat carry genes regulating total nucleolar volume}

In stocks with the long arm of chromosome $6 \mathrm{~B}$ deleted, total nucleolar volume is almost twice that in euploid. The volumes of the $1 \mathrm{~B}, 6 \mathrm{~B}, 5 \mathrm{D}$ and $1 \mathrm{~A}$ nucleoli are all increased. When the whole of chromosome $6 \mathrm{~B}$ is deleted the volume is still higher than that in euploid even though a pair of major nucleoli have been deleted (table 4). This effect is principally due to a doubling of the $1 \mathrm{~B}$ nucleolar volume (see table 4). Thus we conclude that a gene or genes controlling (reducing) nucleolar volume resides on the long arm of chromosome $6 \mathrm{~B}$ of Chinese Spring wheat.

A gene which similarly reduces nucleolar volume resides on chromosome $1 \mathrm{D}$ of Chinese Spring because in stocks with the chromosome deleted (NIDTIA, CS(1D)1U) volumes are significantly increased (table 5). In this case the gene appears to be on the short arm of the chromosome because nucleolar volume is also significantly increased in DTIDL. The increase in total nucleolar volume in the $6 \mathrm{BS}$ and $1 \mathrm{D}$ deletion stocks is associated with an increase in visible micronucleoli which indicates that the activity of the 5D and/or $1 \mathrm{~A}$ nucleolar organisers also responds to the absence of the suppressor genes. It would thus appear that the suppressor genes on chromosomes 6B and ID affect all four NORs in a similar way.

In the previous study into the genetic control of the number of nucleoli observed per cell, altering the dosage of thirteen different chromosomes not carrying rDNA was found to affect the
Table 5 The effect of varying different chromosomes on nucleolar volume of root tip celfs

\begin{tabular}{lc}
\hline Genotype & $\begin{array}{l}\text { Total volume } \\
\left(\mu \mathrm{m}^{3}\right)\end{array}$ \\
\hline CS & $86 \pm 1 \cdot 98$ \\
DT6BS & $214 \pm 5 \cdot 17$ \\
DT1DL & $127 \pm 2 \cdot 65$ \\
N1D T1A & $126 \pm 2 \cdot 04$ \\
CS(1D)1U & $126 \pm 1 \cdot 94$ \\
CS(1A)1U & $108 \pm 2 \cdot 03$ \\
Tet 2A & $78 \pm 2 \cdot 04$ \\
Tet 2B & $81 \pm 2 \cdot 13$ \\
Tet 2D & $82 \pm 1 \cdot 94$ \\
Tet 3A & $77 \pm 2 \cdot 20$ \\
Tet 3B & $79 \pm 1 \cdot 81$ \\
Tet 3D & $85 \pm 1 \cdot 85$ \\
Tet 4A & $84 \pm 1 \cdot 99$ \\
Tet 4D & $84 \pm 2 \cdot 01$ \\
\hline
\end{tabular}

expression of the 5D and/or 1A NORs which suggests that these chromosomes carry genes affecting the volume of at least the micronucleoli (Flavell and O'Dell 1979). We therefore studied the total nucleolar volume of some of these stocks. None of those studied (T2A, T2B, T2D, T3A, T3B, T3D, T4A, T4D) had total nucleolar volumes which differed substantially from the control (table 5 ). Thus the effect of altering the dosage of these chromosomes is not equivalent for all NORs, in contrast to altering the dosage of chromosome $6 \mathrm{~B}$ or $1 \mathrm{D}$.

\section{DISCUSSION}

The results in this paper on nucleolus number and volume endorse and extend those of previous studies (Flavell and O'Dell, 1979). The volume appears to be regulated by many factors. These include the proportion of the total potentially active rRNA genes in the cell which reside at the NOR in question (Flavell and O'Dell, 1979) as illustrated by the increase in the volume of specific nucleoli following deletion of other NORs from the cell (table 4). Many non NOR genes also influence nucleolar volume. Some, such as those on chromosomes 1D and 6B (table 5) appear to affect all nucleoli similarly while those on thirteen other chromosomes (table 4 and table 5; Flavell and O'Dell, 1979) appear to affect some NORs differentially. This differential effect could be due to the specific enlargement of some nucleoli or the inhibition of others.

The existence of a complex genetic control system for nucleolar activity in wheat is not surprising since there is a large excess of rDNA and many 
rDNA loci (NORs) which provide considerably more potential for ribosome production over that required.

Nucleolar volume increases rapidly during the early part of each cell cycle. The final volume attained differs for different cell types. The nucleolus formed in the haploid, developing pollen cell is particularly large. However, the genetic variation affecting nucleolar volume appears to similarly influence root tip, premeiotic and young pollen cells (fig. 4).

The nucleolus contains rDNA chromatin, and ribonucleoprotein particles as well as other structural components. Variation in nucleolar volume could result from different amounts of transcriptionally active chromatin, different rates of transcription of a similar amount of rDNA chromatin, different rates of assembly of ribosomes or different rates of export of ribosomes. To determine which of these is relevant to the variation in nucleolar volume described here, further studies will be necessary.

\section{REFERENCES}

BIRNSTIEL, M. L., CHIPCHASE, M. AND SPIERS, J. 1971. The ribosomal RNA cistrons. Progress in nucleic acid and molecular biology, 11, 351-389.

FLAVELL, R. B. AND ODELL, M. 1976. Ribosomal RNA genes on homoeologous chromosomes of groups 5 and 6 in hexaploid wheat. Heredity, 37, 377-385.
FLAVELL, R. B. AND O'DELL, M. 1979. The genetic control of nucleolus formation in wheat. Chromosoma, 71, 135-152.

FLAVELL, R. B. AND SMITH, D. B. 1974. The role of homeologous group 1 chromosomes in the control of rRNA genes in wheat. Biochemical Genetics, 12, 271-279.

FLAVELL, R. B. AND MARTINI, G. 1982. The genetic control of nucleolus formation with special reference to common breadwheat. In Society Experimental Biology Symposium. (ed.) Cullis, C. A. and Jordan, E. G., Cambridge University Press.

GOESSENS, G. AND LAPOINT, A. 1974. The fine structure of the nucleolus during metaphase and mitosis in Ehrlich tumor cells cultivated in vitro. Experimental Cell Research, 87, 63-72.

JORDAN, E. G. AND Cullis, C. A. 1982. The Nucleolus. Cambridge University Press.

JORDAN, E. G., MARTINI, G., BENNETT, M. D. AND FLAVELL, R. B. 1982. Nucleolar fusion in wheat. J. Cell Science, 56, 485-495.

LONGWELL, A. C. AND SVIHLA, G. 1960. Specific chromosomal control of the nucleolus and of the cytoplasm in wheat. Experimental Cell Research, 20, 294-312.

MADAN, B. E. H., HALL, L. M., AND SALIN, M. 1982. Ribosome formation in the eucaryotic nucleolus: recent advances from sequence analysis. In The Nucleolus. Jordan, E. G., Cullis, C. A., Cambridge University Press, 87-101.

MILLER, L. AND KNOWLAND, J. 1970. Reduction of Ribosomal RNA synthesis and ribosomal RNA genes in a mutant of Xenopus laevis which organises on a partial nucleolus. II. The number of ribosomal RNA genes in animals of different nucleolar types. J. Mol. Biol., 53, 329-338.

RATTENBURY, J. A. 1952. A specific staining of nucleolar substance with aceto-carmine. Stain Technol, 27, 113.

SEARS, E. R. 1954. The aneuploids of common wheat. Missouri Agricultural Experimental Station Research Bulletin 572, $1-59$.

SHERMOEN, A. W. AND KIEFER, B. I. 1975. Regulation in rDNA deficient Drosophila melanogaster. Cell, 4, 275-280.

WEBER, D. F. 1978. Nullisomic analysis of nucleolar formation in Zea mays. Canad. J. Genet. Cytol., 20, 97-100. 